Open Access

\title{
Evaluation of two treatment strategies for the prevention of preterm birth in women identified as at risk by ultrasound (PESAPRO Trial): study protocol for a randomized controlled trial
}

Lourdes Cabrera-García', Sara Cruz-Melguizo ${ }^{2}$, Belén Ruiz-Antorán ${ }^{1 *}$, Ferrán Torres ${ }^{3}$, Ana Velasco ${ }^{4}$, Cristina Martínez-Payo², Cristina Avendaño-Solá', on behalf of the PESAPRO trial Group

\begin{abstract}
Background: Premature birth is considered one of the main problems in modern Obstetrics. It causes more than $50 \%$ of neonatal mortality; it is responsible for a large proportion of infant morbidity and incurs very high economic costs. Cervical length, which can be accurately measured by ultrasound, has an inverse relationship with the risk of preterm birth. As a result, having an effective intervention for asymptomatic patients with short cervix could reduce the prematurity. Although recently published data demonstrates the effectiveness of vaginal progesterone and cervical pessary, these treatments have never been compared to one another.

Methods/Design: The PESAPRO study is a noncommercial, multicenter, open-label, randomized clinical trial (RCT) in pregnant women with a short cervix as identified by transvaginal ultrasonography at 19 to 22 weeks of gestation. Patients are randomized (1:1) to either daily vaginal progesterone or cervical pessary until the 37th week of gestation or delivery; whichever comes first. During the trial, women visit every 4 weeks for routine questions and tests. The primary outcome is the proportion of spontaneous preterm deliveries before 34 weeks of gestation. A sample size of 254 pregnant women will be included at 29 participating hospitals in order to demonstrate noninferiority of placing a pessary versus vaginal progesterone. The first patient was randomized in August 2012, and recruitment of study subjects will continue until the end of December 2015.
\end{abstract}

Discussion: This trial assesses the comparative efficacy and safety between two accepted treatments, cervical pessary versus vaginal progesterone, and it will provide evidence in order to establish clinical recommendations.

Trial registration: EU Clinical Trials Register EudraCT2012-000241-13 (Date of registration: 16 January 2012); ClinicalTrials.gov Identifier NCT01643980 (Date of registration: 12 June 2012).

Keywords: premature birth, short cervix, vaginal progesterone, cervical pessary, prevention

\footnotetext{
* Correspondence: mariabelen.ruiz@salud.madrid.org

${ }^{1}$ Clinical Pharmacology Service, University Hospital Puerta de Hierro -

Majadahonda, Manuel de Falla, 1, 28222 Majadahonda, Madrid, Spain

Full list of author information is available at the end of the article
} 


\section{Background}

Preterm birth, defined as birth before 37 weeks of gestation, is the second most frequent direct cause of infant death in children younger than 5 years old [1-4]. Preterm birth is considered a major problem in modern Obstetrics, and it is the leading cause of perinatal morbidity and mortality in developed countries [5]. It is also associated with an important economic burden [6,7]. Despite significant medical advances, the rate of prematurity has not declined over the past 40 years; rather, it has continued to rise. An increase in maternal age and underlying maternal health problems, such as diabetes and hypertensive disorders or iatrogenic factors like greater use of infertility treatments, which lead to increased rates of multiple pregnancies and changes in obstetric practices (such as more caesarean births before term) [8] have been identified as different reasons that explain this phenomenon. The prevalence of preterm births is about 12 to $13 \%$ in the United States of America and 5 to $9 \%$ in the European Union and other developed countries [5]. Although all deliveries before 37 weeks of gestation are considered preterm, the highest proportion of complications and neonatal death occur in those born at less than 34 weeks.

In order to reach an effective decrease of prematurity, two premises are necessary: to identify pregnant women who are at risk and to dispose of measures that serve to extend pregnancy, thus avoiding the prematurity. Some published papers describe sonographic measurement of the cervix at the 16th week as a method of screening to detect women at risk of spontaneous preterm delivery [3, 9-11]. In 1996 [1], Iams et al. demonstrated that the risk of preterm delivery is inversely proportional to the length of the cervix on transvaginal ultrasonography (US) between 24 and 28 weeks of gestation in a nonselected population in the United States of America.

After this publication [1], several studies have shown that the risk of preterm birth was inversely correlated to the length of the cervix as measured by transvaginal ultrasound $[2,3,9,12,13]$, which has been confirmed in a recent meta-analysis [14].

Therefore, considering that the risk of prematurity is inversely proportional to cervical length, cervical measurement constitutes a method of screening for use in pregnant women who are asymptomatic before 24 weeks [15-17]. For decades, different types of therapeutic intervention have been explored in order to decrease preterm births, including primary prevention measures (all pregnant women), secondary prevention measures (only in women at risk) or tertiary prevention measures (initiated after the delivery process has started) [18]. A recent review concluded that there was insufficient evidence to provide sound recommendations for clinical practice in approximately half of the evaluated interventions [19]. Nevertheless, according to several trials and systematic reviews, two strategies, vaginal progesterone [20-28] and silicon cervical pessary [29-32], have been shown to be effective at decreasing the rate of spontaneous delivery before 34 weeks of gestation in at-risk women who have a short cervix.

Progesterone is a key hormone during gestation that has uterus-relaxing effects. Low levels of progesterone are associated with a high grade of cervix maturation and, consequently, a shorter cervical length and a higher risk of spontaneous delivery. The administration of progesterone supplements decreases preterm delivery in women with a short cervix [20-23] and in pregnant women with a history of preterm births $[25,26]$.

In March 2012, Romero et al. published a metaanalysis [27], which explored whether the use of vaginal progesterone in asymptomatic women whose ultrasound showed a short cervix (under $25 \mathrm{~mm}$ ) in the second trimester reduced the risk of preterm birth and improved neonatal morbidity and mortality.

Five relevant clinical trials, which included a total of 775 women and 827 infants, were analyzed. The results showed that treatment with vaginal progesterone was associated with a significant reduction in the preterm birth rate before 33 weeks $(12.4 \%$ versus $22.0 \%$; relative risk (RR) 0.58 ; $95 \%$ confidence interval (CI), 0.42 to 0.80 ), <35 weeks (RR, 0.69; $95 \% \mathrm{CI}$, 0.55 to 0.88 ), and $<28$ weeks (RR, $0.50 ; 95 \% \mathrm{CI}, 0.30$ to 0.81 ); respiratory distress syndrome (RR, $0.48 ; 95 \%$ CI, 0.30 to 0.76 ); composite neonatal morbidity and mortality (RR, 0.57; $95 \% \mathrm{CI}, 0.40$ to 0.81 ); birth weight $<1500 \mathrm{~g}$ (RR, $0.55 ; 95 \% \mathrm{CI}, 0.38$ to 0.80 ); admission to neonatal intensive care unit (RR, 0.75; $95 \%$ CI, 0.59 to 0.94 ); and requirement for mechanical ventilation ( $R R, 0.66 ; 95 \% \mathrm{CI}, 0.44$ to 0.98 ). There were no significant differences in the rate of adverse maternal events or congenital anomalies between the vaginal progesterone and placebo groups. The authors concluded that the data provides sufficient evidence about the benefit of vaginal progesterone to prevent the preterm birth in women with a sonographic short cervix. They recommend measuring cervical length using transvaginal sonogram at 19 to 24 weeks of gestation.

Although cervical pessaries were introduced for management of cervical incompetence [33-35] at the end of the 1950s, a very limited number of papers regarding the use of pessaries in pregnant women have been found. In a case control study, Arabin et al. [29] observed that the prematurity rate significantly decreased in singleton and twin pregnancies in women with a short cervix in comparison with the controls when pessaries were used. 
The first randomized study using a pessary (PECEP trial) was published in 2012 [30]. A total of 385 pregnant women with singleton pregnancies and a cervix length of $\leq 25 \mathrm{~mm}$ detected through vaginal ultrasonography at 18 to 22 weeks of gestation were randomized (1:1) to cervical pessary or expectant management. A significant reduction (76 \%) in spontaneous deliveries before 34 weeks was found in the pessary group (6.3\% versus $26.8 \%$; odds ratio 0.18 , $95 \%$ CI 0.08 to $0.37 ; P<0.0001)$. In addition, a decrease in low-weight neonates $(<2500 \mathrm{~g})$ was detected $(6.3 \%$ versus $29.5 \%$; odds ratio $0.23,95 \% \mathrm{CI}$ 0.12 to $0.43 ; P<0.0001)$. After the PECEP publication, it was suggested [31] that more studies are needed in different settings to confirm the results of this single trial.

Finally, regarding safety, it is worth highlighting that natural, micronized vaginal progesterone is a medicine that can be administered either orally or vaginally. There are no described adverse reactions in the product monograph when it is administered vaginally. Some women have reported a slight increase in vaginal discharge [36]. Cervical pessary can produce an increase in vaginal discharge, but without an increase in bacterial vaginosis or corioamnionitis in pregnant women. Although slight discomfort can sometimes occur during pessary placement, most patients note that the discomfort is acceptable [30].

Because of the published data, ultrasound measurement of the cervix is being progressively incorporated into clinical practice and either pessary or progesterone is increasingly being used in women with a short cervix. However, there is a "therapeutic hole" and neither of the two strategies is approved for this indication. In order to clear up any doubts about the potential benefits of both treatments and to establish clinical recommendations, comparative data are necessary. Alfirevic et al. [37] compared three different cohorts using cervical pessary, vaginal progesterone or cerclage for women with a singleton pregnancy and a high risk of preterm birth due to a prior spontaneous preterm birth before 34 weeks and a shortened cervical length as detected by transvaginal ultrasound. Their data suggests that the three treatments are a reasonable option in this population and they concluded that direct randomized comparisons of these strategies are needed.

The main objective of the PESAPRO trial is to compare the efficacy of two treatments, vaginal progesterone and cervical pessary, in terms of decreasing the rate of spontaneous preterm births before 34 weeks of gestation in women with a short cervix, which has been detected by transvaginal ultrasonography.

\section{Methods/Design}

PESAPRO is a noncommercial, national, multicenter, randomized, open-label trial designed to compare the effect on premature birth prevention of two currently accepted strategies: administration of progesterone (vaginally) or the placement of vaginal pessaries in pregnant women with a short cervix $(\leq 25 \mathrm{~mm})$ as diagnosed by transvaginal ultrasonography (US) in the second trimester morphology ultrasound.

The inclusion of a third arm with placebo control was discussed in the original design because it would have been a valuable tool from a methodological point of view.- However, it was later discarded due to ethical and feasibility issues after taking into consideration the most recent publications.

\section{Participating centers}

Thirty-one hospitals are currently participating in the PESAPRO trial. Fourteen center had initially been invited to participate, and, later, 17 additional hospitals were incorporated into the trial in a second phase.

All participating Obstetrics Units routinely perform transvaginal ultrasonography in the second term as a screening diagnosis method to detect women at risk of preterm birth (listed in Appendix 1).

\section{Study population and trial development}

Pregnant women with a short cervix $(\leq 25 \mathrm{~mm})$ as identified by routine transvaginal ultrasonography at 19 to 22 weeks of gestation are eligible to enroll. Before the evaluation, the woman should have an empty bladder and be placed in the dorsal lithotomy position. The vaginal probe should be placed in the anterior fornix without pressure. Initial orientation is established by locating the sagittal view of the cervix. The length of the endocervical canal should be measured in a straight line from the internal to the external cervix. The cervix is dynamic; therefore, three measurements should be made over a 3-minute period, and the shortest measurement reported for clinical use $[16,38]$. During this routine ultrasonography in the second term, singleton-pregnancy women with a short cervix $(\leq 25 \mathrm{~mm})$ are considered to participate in the PESAPRO trial. Table 1 shows the inclusion and exclusion criteria. A member of the research team informs the patient about the clinical trial during this (second trimester ultrasound) visit or at a different time, according to investigator criteria. Once informed consent has been obtained and baseline data has been collected (demographic, medical and obstetric history, vaginal and endocervix samples for culture), participants are individually randomized to vaginal progesterone or pessary. Study participants are evaluated every four weeks ( \pm 7 days) for a total 
Table 1 Inclusion and exclusion criteria for PESAPRO

\begin{tabular}{|c|c|}
\hline Inclusion criteria & Exclusion criteria \\
\hline - Women older than 18 years old & - Major fetal and/ or uterine abnormalities \\
\hline $\begin{array}{l}\text { - Pregnant women with a short cervix }(<25 \mathrm{~mm}) \text { identified by the } \\
\text { use of routine transvaginal ultrasonography at } 19 \text { to } 22 \text { weeks } \\
\text { of gestation }\end{array}$ & - Placenta previa during current pregnancy \\
\hline $\begin{array}{l}\text { - Gestational age at randomization between } 20 \text { weeks }+1 \text { and } \\
23 \text { weeks }+6\end{array}$ & - Vaginal bleeding or ruptured membranes in the moment of randomization \\
\hline - Single pregnancy & - Cervical cerclage in situ \\
\hline \multirow{7}{*}{$\begin{array}{l}\text { - Women sign informed consent according to the GCP and local } \\
\text { legislation }\end{array}$} & - History of cone biopsy \\
\hline & - History of three or more premature labor \\
\hline & - Allergic to peanut \\
\hline & - Contraindication for progesterone usage \\
\hline & - Active treatment with progesterone at randomization \\
\hline & $\begin{array}{l}\text { - If in an investigator's opinion, there are findings on physical examination, abnormalities } \\
\text { in the results of clinical analyzes or other medical factors, social or psychosocial that } \\
\text { could negatively influence }\end{array}$ \\
\hline & -Women unable to give the informed consent \\
\hline
\end{tabular}

of four visits; routine assessments (such as blood pressure, and weight), cervicometry and fetal ultrasonography are performed during each visit to assess adverse events and compliance with the study medication (in the progesterone group). Women are asked to return unused study medication from the previous 4 weeks and compliance is determined on the basis of the amount of the study drug that is unused. Study treatments continue until the third term $(37$ to $37+4$ weeks), when the obstetrician removes the pessary, collects all the leftover medication, or until delivery, whichever occurs first.

Any patients who develop preterm labor during the study are treated according to the standard practice of the participating institution. The study treatments continue during hospitalization until the moment at which delivery is unavoidable or until completion of gestation is indicated. One additional assessment (medical record review or phone call) is performed 4 to 6 weeks after delivery in order to collect full data. See Table 2 for the detailed schedule of enrollment and assessments.

\section{Randomization}

Consecutive eligible patients are randomly allocated in a 1:1 ratio to one of the two treatment groups: vaginal progesterone or cervical pessary. The randomization sequence is computer generated (by EpiDat program). It is protected and it is managed exclusively by the Clinical Pharmacology Unit at University Hospital Puerta de Hierro - Majadahonda, which has no role in recruitment.
The investigators receive the patient's identification (ID) number and the assigned treatment by a central phone call, after having been informed that a new patient has entered into the trial. An auditable registry of the date and time of inclusion, patient ID number and treatment assignment is stored in the sponsor's records.

\section{Study interventions}

Two accepted treatments in the management of preterm birth risk are being assessed in the PESAPRO trial, although neither of them is approved for use in this condition. For statistical purposes, we consider the pessaries to be the experimental group and progesterone to be the reference (or comparator) group. Patients who are assigned to the comparator group receive $200 \mathrm{mg}$ of $\mathrm{mi}-$ cronized progesterone per day by vaginal route; women self-administer the medicine once daily, preferably before going to bed.

The cervical pessary used in this study is a perforated-cerclage type pessary, a hypoallergenic silicon medical device certified by European Conformity, size 65/25/32 (65 $\mathrm{mm}$ lower larger diameter, $25 \mathrm{~mm}$ height and $32 \mathrm{~mm}$ upper smaller diameter). The pessary is disposed of (and removed) by qualified personnel (Obstetrician) at the clinic. Both treatments are withdrawn between the 37 th week and 37 week +4 .

\section{Treatment registry}

During the trial, both treatments are being properly registered. The commercial progesterone used (PROGGEFFIK ${ }^{\mathrm{TM}}$ ) 
is re-labelled in the Clinical Trials Pharmacy Unit of the University Hospital Puerta de Hierro - Majadahonda and then distributed to all participating centers. The label includes the following data: trial code, sponsor name, investigational product, batch number, expiration date and the trial subject identification number. Regarding the pessary, the batch number and the expiration date also are being registered.

\section{Study outcomes}

The primary outcome measure is the proportion of spontaneous preterm birth before 34 weeks of gestation. The secondary outcomes are the following: proportion of spontaneous preterm birth before the 37th and 28th weeks, the rate of premature rupture of membranes before 34 weeks, the neonate's weight at birth, the rate of fetal intrauterine mortality during the treatment period, the rate of neonatal morbidity and mortality, the need for hospitalization and tocolysis treatment, the rate of chorioamnionitis during the third term, symptomatic vaginal infections during the treatment period and the proportion of participants with adverse events.

\section{Statistical analysis}

A sample size of 254 women (127 women per arm) was predefined to show the noninferiority of the experimental group (pessary) versus the reference group (progesterone), assuming a proportion of preterm birth (before
34 weeks) of $6 \%$ and $12.4 \%$, respectively, with a noninferiority margin of $4 \%$, a $2.5 \%$ one-sided alpha level, a statistical power of $80 \%$ and a drop-out rate of $5 \%$.

Statistical analysis will be based on the intentionto-treat principle and a sensitivity analysis using the per-protocol subset for the main outcome will be used for sensitivity purposes. The noninferiority hypothesis will be tested by estimating treatment rate differences against the noninferiority margin. The survival function and the median $(95 \%$ confidence interval (CI)) time to delivery will be estimated by means of the Kaplan-Meier method and treatment effects will be compared using the log-rank test and hazard ratios (HR) $(95 \% \mathrm{CI}$ ) will be taken from the Cox model. The rest of the variables will be analyzed using the Fisher's exact test to compare categorical data, the t-test for continuous variables and the Mann- Whitney test for ordinal and non-normally distributed variables.

The analysis will be performed using SAS v9.2, or a newer version, software (SAS Institute Inc., Cary, NC, USA), and the level of significance will be set at $5 \%$ (two-sided).

\section{Organization of the trial}

PESAPRO is a noncommercial trial organized by the Obstetrics and Gynecology Department and the Clinical

Table 2 Schedule of PESAPRO study's visit

\begin{tabular}{|c|c|c|c|c|c|c|c|c|}
\hline & $\begin{array}{l}\text { Visit } 1 \text { (Routine } \\
\text { control } 2 \text { term) }\end{array}$ & $\begin{array}{l}\text { Inform } \\
\text { Visit }\end{array}$ & $\begin{array}{l}\text { Visit } 0 \text { basal } \\
(20 \text { weeks }+1 \\
\text { to } 23 \text { weeks }+6)\end{array}$ & $\begin{array}{l}\text { Visit } 1 \\
\text { (Vo + } 4 \text { weeks) }\end{array}$ & $\begin{array}{l}\text { Visit } 2 \\
(V 1+4 \text { weeks })\end{array}$ & $\begin{array}{l}\text { Visit } 3 \\
\text { (V2 + } 4 \text { weeks) }\end{array}$ & $\begin{array}{l}\text { Visit } 4 \text { (EOT) } \\
(37 \text { weeks to } \\
37 \text { weeks + 4) }\end{array}$ & $\begin{array}{l}\text { Post-delivery } \\
\text { visit ( } 4 \text { to } 6 \text { weeks } \\
\text { post-delivery) }\end{array}$ \\
\hline Eligibility criteria & & $\sqrt{ }$ & $\sqrt{ }$ & & & & & \\
\hline Informed consent & & & $\sqrt{ }$ & & & & & \\
\hline $\begin{array}{l}\text { Randomization and } \\
\text { start of treatment }\end{array}$ & & & $\sqrt{ }$ & & & & & \\
\hline $\begin{array}{l}\text { Blood pressure/ } \\
\text { weight }\end{array}$ & & & $\sqrt{ }$ & $\sqrt{ }$ & $\sqrt{ }$ & $\sqrt{ }$ & $\sqrt{ }$ & \\
\hline Vaginal culture & & & $\sqrt{ }$ & & & & & \\
\hline $\begin{array}{l}\text { Manual vaginal } \\
\text { exam }\end{array}$ & & & $\sqrt{ }$ & & & & $\sqrt{ }$ & \\
\hline Cervicometry & $\sqrt{ }$ & & $\sqrt{ }$ & $\sqrt{ }$ & $\sqrt{ }$ & $\sqrt{ }$ & $\sqrt{ }$ & \\
\hline $\begin{array}{l}\text { Follow-up } \\
\text { Questionnaire }\end{array}$ & & & & $\sqrt{ }$ & $\sqrt{ }$ & $\sqrt{ }$ & $\sqrt{ }$ & \\
\hline Basic fetal US & & & $\sqrt{ }$ & $\sqrt{ }$ & & $\sqrt{ }$ & $\sqrt{ }$ & \\
\hline $\begin{array}{l}\text { End of treatment } \\
\text { (EOT) }\end{array}$ & & & & & & & $\sqrt{ }$ & \\
\hline $\begin{array}{l}\text { Review maternal } \\
\text { medical history }\end{array}$ & & & $\sqrt{ }$ & & & & & $\sqrt{ }$ \\
\hline $\begin{array}{l}\text { Review neonate } \\
\text { medical history }\end{array}$ & & & & & & & & $\sqrt{ }$ \\
\hline
\end{tabular}

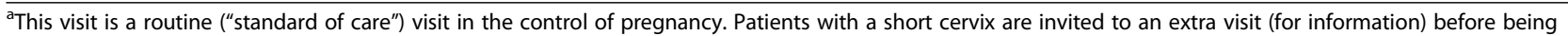
enrolled in the study 
Pharmacology Unit of the University Hospital Puerta de Hierro - Majadahonda. The sponsor role is taken by C. Martinez-Payo. The medical coordinator of the trial is $\mathrm{S}$. Cruz Melguizo. The Clinical Pharmacology Unit oversees the methodological and organizational aspects of the study. Since 2014, the study has been receiving support from the Spanish Clinical Research network (SCReN) for regulatory and administrative support, monitoring, data management and pharmacovigilance. The PESAPRO study group comprised of all clinical investigators at the participating centers and the collaborators from the Clinical Pharmacology Unit.

\section{Funding/Support}

The study is fully funded with public funds obtained in competitive calls: grant PT13/0002/0005 (SCReN-Spanish Clinical Research Network) from the National R+D+I 2013-2016 Plan of the Institute of Health Carlos III (AES 2013), grant EC11/086 of the Ministry of Health Call for Independent Clinical Research in year 2011, and grant PI12/02240 from the Institute of Health Carlos III, ISCIII, from the National I+D+I 2008-2011 Plan and co-financed by FEDER funds.

\section{Coordination and conduct of the trial}

The study is coordinated by the Obstetrics and Gynecology Unit and the Clinical Pharmacology Unit (Appendix 2). Three investigator meetings have been held in order to review the study protocol and data collection in the electronic case report form (eCRF). Additionally, after the necessary approvals were obtained, a meeting was held in each hospital before the start of patient recruitment procedures. All documents required for the study are available at each participating site. The eCRF is a secure, interactive, web-response system available at each study center, provided and managed by the Biostatistics and Data Management Core Facility of Institut d'investigacions Biomèdiques August Pi i Sunyer (IDIBAPS) Hospital Clínic, Barcelona.

In each participating Obstetrics Unit, the physicians and research personnel (research nurse or assistant) are in charge of patient screening and inclusion, ensuring compliance with the study protocol and collecting the study data in the eCRFs. The trial is being monitored by an independent monitor. The monitor regularly reviews the eCRFs, ensuring compliance with the trial protocol, data completeness and data accuracy. All adverse events and serious adverse events are being recorded according to standard procedures.

\section{Ethical considerations}

The trial has been registered at European Clinical Trial Database (EUDRACT2012-000241-13) and at ClinicalTrials.gov (NCT01643980). The study is being conducted in accordance with Good Clinical Practice guidelines, the guiding principles of the Declaration of Helsinki, and applicable local regulations. The study was approved by the Spanish National Competent Authority (AEMPS) and by the Research Ethics Committees of the participating centers (listed in Appendix 3). Any relevant protocol amendments will be submitted to the competent Ethics Committee for review and will be updated in the trial registries. Participants are provided with information sheets and written informed consent is obtained prior to recruitment and baseline assessment.

A specific insurance policy has been contracted to cover compensations to patients in the event of injuries, in compliance with the requirements of Spanish law regarding clinical trials.

Although a third control arm with placebo is very valuable from a methodological point of view in a noninferiority comparative trial, it was discarded in our trial. The main reason was related to the fact that most participant hospitals were already treating these women with a short cervix (either with a pessary or with progesterone) as a measure to decrease the risk of preterm birth, based on recent publications. Although confirming data with regards to the superiority of both treatments versus placebo would have been highly valuable, it was considered ethically questionable.

\section{Discussion}

Preterm birth is a major public health problem with a relevant neonatal morbimortality. It has been established that a short cervix $(\leq 25 \mathrm{~mm})$ diagnosed by transvaginal ultrasonography in the second trimester constitutes an important risk factor of preterm delivery [1, 9, 11, 39]. Although several therapeutic strategies (vaginal progesterone, cervical pessary and cerclage) have been used in these women showing a potential benefit, they have never been compared to one another in randomized trials. This study will assess the comparative efficacy of two of these three treatments (vaginal progesterone versus pessary). It is possible that the results of this study will contribute to the establishment of clinical recommendations regarding the use of both treatments in the prevention of preterm delivery in women with a short cervix.

\section{Trial status}

Patient inclusion to the PESAPRO trial began in September 2012. Enrollment is ongoing. The study is being conducted at 29 investigational sites. As of May 2015, 190 patients had been included in the study. Patient recruitment is expected to end in July 2015. 


\section{Appendix 1}

Table 3 PESAPRO trial sites and principal investigators

\begin{tabular}{|c|c|c|}
\hline Site ID & Trial sites & Principal investigators \\
\hline \multirow[t]{2}{*}{1} & \multirow[t]{2}{*}{ Hospital Puerta de Hierro Majadahonda } & Dra. Cristina Martínez Payo \\
\hline & & Dra. Sara Cruz Melguizo \\
\hline 2 & Hospital Príncipe de Asturias & Dra. Estefanía Cordero \\
\hline 3 & Hospital de Alcorcón & Dr. Begoña Adiego Burgos \\
\hline 4 & Hospital General Yagüe & Dr. Javier Martínez Guisasola \\
\hline 5 & Hospital de Getafe & Dr. Luis Martínez Cortés \\
\hline 6 & Hospital de León & Dr. Celso García González \\
\hline 7 & Hospital Río Hortega & Dr. Gonzalo Quesada Segura \\
\hline 8 & Hospital Ramón y Cajal & Dr. Leopoldo Abarca \\
\hline 9 & Hospital Miguel Servet & Dr. Ricardo Savirón \\
\hline 11 & Hospital Infanta Elena & Dra. Esther Pérez Carbajo \\
\hline 12 & Hospital InfantaSofía & Dr. José Alberto Rodríguez León \\
\hline 13 & Hospital La Paz & Dr. José Luis Bartha \\
\hline 14 & Hospital de Fuenlabrada & Dra. MaríaTeulón \\
\hline 16 & Hospital Universitario Rey Juan Carlos I & Dra. Rosa Nogales \\
\hline 17 & Hospital UniversitarioQuiron Dexeus & Dr. Rodríguez \\
\hline 18 & Hospital UniversitarioSevero Ochoa & Dra. Gregoria Alonso \\
\hline 19 & Hospital Clínico Universitario de Valladolid & Dra. Cristina Álvarez Colomo \\
\hline 20 & Hospital General Universitario de Ciudad Real & Dra. M Ángeles Anaya Baz \\
\hline 21 & Hospital Quirón Málaga & Dr. Daniel Abehsera Davó \\
\hline 22 & Hospital Universitario de Guadalajara & Dra. Maria Jesús Cancelo \\
\hline 23 & Hospital Sanitas la Zarzuela & Dra. Elisa Maria Díaz De Teran \\
\hline 24 & Hospital d’lgualada & Dr. Joan Carles Mateu Pruñunosa \\
\hline 25 & Hospital Madrid UniversitarioMonteprincipe & Dra. Gloria Gálvez \\
\hline 26 & Hospital Universitario Reina Sofía & Dr. Antonio de la Torre \\
\hline 27 & Hospital Palamos (ComarcalBaixEmporda) & Dr. José Manuel Marqueta Sánchez \\
\hline 28 & Hospital Universitario San Juan de Alicante & Dra. Rosa Bermejo \\
\hline 29 & Hospital Universitario de Donostia & Dra. Arantza Lekuona Artola \\
\hline 30 & Hospital Sanitas La Moraleja & Dr. Eduardo Cabrillo Rodríguez \\
\hline 31 & Hospital Universitario de Móstoles & Dra. Emilia de Dios \\
\hline
\end{tabular}

\section{Appendix 2}

\section{Steering committee}

Sara Cruz Melguizo, Cristina Martínez-Payo, Luis San Frutos, Francisco López Sánchez, Cristina Avendaño Solá, Belén Ruiz Antorán, and Lourdes Cabrera García.

\section{Data safety monitoring committee}

- Dra. Caridad Pontes: Consultant Physician at Hospital de Sabadell.
- Dr. José Ríos: Statistician Coordinator of the Platform of Biostatistics and data Management core and facilityb at the IDIBAPS (Hospital Clinic Barcelona).

- Dr. Tirso Pérez: Head of Gynecology at Hospital Universitario Puerta de Hierro Majadahonda. 


\section{Appendix 3}

Table 4 Research Ethics Committees that approved the study in the various centers involved

\begin{tabular}{|c|c|c|c|}
\hline $\begin{array}{l}\text { Site } \\
\text { ID }\end{array}$ & Trial sites & Principal investigators & Research Ethics Committees ethical \\
\hline 1 & Hospital Puerta de Hierro-Majadahonda & Dra. Sara Cruz Melguizo & CEIC H.U. Puerta de Hierro-Majadahonda (REFERENCE) \\
\hline 2 & Hospital Príncipe de Asturias (Alcalá de Henares) & Dra. Estefanía Cordero & CEIC H.U. Príncipe de Asturias \\
\hline 3 & Hospital de Alcorcón & Dr. Begoña Adiego Burgos & CEIC Fundación Hospital Alcorcón \\
\hline 4 & Hospital General Yagüe (Burgos) & Dr. Javier Martínez Guisasola & CEIC Área de Salud de Burgos y Soria \\
\hline 5 & Hospital de Getafe & Dr. Luis Martínez Cortés & CEIC H.U. Getafe \\
\hline 6 & Hospital de León & Dr. Celso García González & Área de Salud de León \\
\hline 7 & Hospital Río Hortega (Valladolid) & Dr. Gonzalo Quesada Segura & Área de Salud de Valladolid Oeste \\
\hline 8 & Hospital Ramón y Cajal & Dr. Leopoldo Abarca & CEIC H.U. Ramón y Cajal \\
\hline 9 & Hospital Miguel Servet (Zaragoza) & Dr. Ricardo Savirón & Aragón - CEICA \\
\hline 10 & Hospital Marqués de Valdecilla & Dr. Gerardo Ballesteros & CEIC de Cantabria \\
\hline 11 & Hospital Infanta Elena (Valdemoro) & Dra. Esther Pérez Carbajo & CEIC -FJD \\
\hline 12 & Hospital Infanta Sofía & Dr. José Alberto Rodríguez León & CEIC H.U. La Paz \\
\hline 13 & Hospital La Paz & Dr. José Luis Bartha & CEIC H.U. La Paz \\
\hline 14 & Hospital de Fuenlabrada & Dra. María Teulón & CEIC H.U. Fuenlabrada \\
\hline 15 & Hospital La Fe (Valencia) & Dr. Vicente José Diago Almela & CEIC H.U. La Fe \\
\hline 16 & Hospital Universitario Rey Juan Carlos I & Dra. Rosa Nogales & CEIC -FJD \\
\hline 17 & Hospital Universitario Quiron Dexeus & Dr. Rodríguez & CEIC H. U. Quirón Dexeus \\
\hline 18 & Hospital Universitario Severo Ochoa & Dra. Gregoria Alonso & CEIC H. U. Severo Ochoa \\
\hline 19 & Hospital Clínico Universitario de Valladolid & Dra. Cristina Álvarez Colomo & CEIC Área de Salud de Valladolid Este \\
\hline 20 & Hospital General Universitario de Ciudad Real & Dra. M Ángeles Anaya Baz & CEIC H. Gral. U. de Ciudad Real \\
\hline 21 & Hospital Quirón Málaga & Dr. Daniel Abehsera Davó & CEIC Andalucía \\
\hline 22 & Hospital Universitario de Guadalajara & Dra. Maria Jesús Cancelo & CEIC H. Gral. U. de Guadalajara \\
\hline 23 & Hospital Sanitas la Zarzuela & Dra. Elisa Maria Díaz De Teran & CEIC H.U. Puerta de Hierro-Majadahonda \\
\hline 24 & Hospital d'Igualada & Dr. Joan Carles Mateu Pruñunosa & CEIC del Hospital Universitari Bellvitge \\
\hline 25 & Hospital Madrid Universitario Monteprincipe & Dra. Gloria Gálvez & CEIC Hospital de Madrid \\
\hline 26 & Hospital Universitario Reina Sofía & Dr. Antonio de la Torre & CEIC Andalucía \\
\hline 27 & Hospital Palamos (Comarcal Baix Emporda) & Dr. José Manuel Marqueta Sánchez & CEIC Institut d.Assistencia Sanitaria de Girona \\
\hline 28 & Hospital Universitario San Juan de Alicante & Dra. Rosa Bermejo & CEIC Hospital General Universitario San Juan de Alicante \\
\hline 29 & Hospital Universitario de Donostia & Dra. Arantza Lekuona Artola & CEIC de Euskadi \\
\hline 30 & Hospital Sanitas La Moraleja & Dr. Eduardo Cabrillo Rodríguez & CEIC H.U. La Paz \\
\hline 31 & Hospital Universitario de Móstoles & Dra. Emilia de Dios & CEIC H Universitario de Móstoles \\
\hline
\end{tabular}

\section{Abbreviations}

Cl: confidence interval; $\mathrm{CMH}$ : Cochran-Mantel-Haenszel; eCRF: electronic case report form; IDIBAPS: Institutd'investigacions Biomèdiques August Pi i Sunyer; ITT: intention to treat; ISCIII: Institute of Health Carlos III; PP: per protocol; RCT: randomized clinical trials; RR: relative risk; SCReN: Spanish Clinical Research Network; US: ultrasonography; USA: United States of America.

\section{Competing interests}

The authors declare that they have no competing interests.

\section{Authors' contributions}

The protocol was developed by LCG, SCM, BRA, CAS and CMP. SCM is the coordinator investigator of this study. FT and BRA provided advice on statistical analysis. AV is the responsible of monitoring. FT supervised the design of the eCRF. LCG prepared the initial manuscript. All authors reviewed the final manuscript prior to submission. All authors read and approved the final manuscript.

\section{Acknowledgements}

The study has been funded by two national grants from the Spanish Ministry of Health and ISCIII. We thank Silvia Paloma Rodríguez Araque (Clinical 
Pharmacology Service) and Dra. Isabel Millan (Biostatics and Epidemiology Department- University Hospital Puerta de Hierro-Majadahonda)

\section{Author details}

${ }^{1}$ Clinical Pharmacology Service, University Hospital Puerta de Hierro Majadahonda, Manuel de Falla, 1, 28222 Majadahonda, Madrid, Spain. ${ }^{2}$ Obstetrics and Gynecology Department, University Hospital Puerta de Hierro - Majadahonda, Manuel de Falla, 1, 28222 Majadahonda, Madrid, Spain. ${ }^{3}$ Biostatistics and Data Management Core Facility, IDIBAPS Hospital Clínic, 183, Mallorca Street, floor-1, 08036 Barcelona, Spain. ${ }^{4}$ Spanish Clinical Research Network, SCReN-IIS Puerta de Hierro Majadahonda, University Hospital Puerta de Hierro Majadahonda, Manuel de Falla, 1, 28222 Majadahonda, Madrid, Spain.

Received: 7 June 2015 Accepted: 17 September 2015 Published online: 25 September 2015

\section{References}

1. lams JD, Goldenberg RL, Meis PJ, Mercer BM, Moawad A, Das A, et al. The length of the cervix and the risk of spontaneous premature delivery. National Institute of Child Health and Human Development Maternal Fetal Medicine Unit Network. N Engl J Med. 1996;334:567-72.

2. Honest H, Bachmann LM, Coomarasamy A, Gupta JK, Kleijnen J, Khan KS. Accuracy of cervical transvaginal sonography in predicting preterm birth: a systematic review. Ultrasound Obstet Gynecol. 2003;22:305-22.

3. Celik E, To M, Gajewska K, Smith GC, Nicolaides KH. Fetal Medicine Foundation Second Trimester Screening Group. Cervical length and obstetric history predict spontaneous preterm birth: development and validation of a model to provide individualized risk assessment. Ultrasound Obstet Gynecol. 2008;31:549-54.

4. Morken NH. Preterm birth: new data on a global health priority. Lancet. 2012;379:2128-30.

5. Goldenberg RL, Culhane JF, lams JD, Romero R. Epidemiology and causes of preterm birth. Lancet. 2008;371:75-84.

6. Petrou S. Economic consequences of preterm birth and low birthweight. BJOG. 2003:110 Suppl 20:17-23.

7. del Instituto de Información Sanitaria. Ministerio de Sanidad, Servicios Sociales e lgualdad. Datos GRD 2009. http://pestadistico.inteligenciadegestion.msssi.es/ publicoSNS/comun/ArbolNodos.aspx. Accessed 03 Nov 2011.

8. Blencowe $H$, Cousens $S$, Oestergaard MZ, Chou D, Moller AB, Narwal R, et al. National, regional, and worldwide estimates of preterm birth rates in the year 2010 with time trends since 1990 for selected countries: a systematic analysis and implications. Lancet. 2012;379:2162-72.

9. Crane JM, Hutchens D. Transvaginal sonographic measurement of cervical length to predict preterm birth in asymptomatic women at increased risk: a systematic review. Ultrasound Obstet Gynecol. 2008;31:579-87.

10. Matijevic R, Grgic O, Vasilj O. Is sonographic assessment of cervical length better than digital examination in screening for preterm delivery in a lowrisk population? Acta Obstet Gynecol Scand. 2006;85:1342-7.

11. Owen J, Yost N, Berghella V, Thom E, Swain M, Dildy GA, et al. Mid-trimester endovaginal sonography in women at high risk for spontaneous preterm birth. JAMA. 2001;286:1340-8.

12. To MS, Skentou CA, Royston P, Yu CK, Nicolaides KH. Prediction of patientspecific risk of early preterm delivery using maternal history and sonographic measurement of cervical length: a population-based prospective study. Ultrasound Obstet Gynecol. 2006;27:362-7.

13. Owen J. Evaluation of the cervix by ultrasound for the prediction of preterm birth. Clin Perinatol. 2003;30:735-55.

14. Berghella V, Baxter JK, Hendrix NW. Cervical assessment by ultrasound for preventing preterm delivery. Cochrane Database Syst Rev. 2009;3, CD007235. doi:10.1002/14651858.CD007235.pub2.

15. Lim K, Butt K, Crane JM. SOGC Clinical Practice Guideline. Ultrasonographic cervical length assessment in predicting preterm birth in singleton pregnancies. J Obstet Gynaecol Can. 2011;33:486-99.

16. RANZCOG College Statement C-Obs 27: Measurement of cervical length for prediction of preterm birth. 2008. https://www.ranzcog.edu.au/doc/ measurement-of-cervical-length-in-pregnancy.html. Accessed 10 May 2011.
17. Committee on Practice Bulletins-Obstetrics, The American College of Obstetricians and Gynecologists. Practice bulletin no. 130: prediction and prevention of preterm birth. Obstet Gynecol. 2012;120:964-73.

18. lams JD, Romero R, Culhane JF, Goldenberg RL. Primary, secondary, and tertiary interventions to reduce the morbidity and mortality of preterm birth. Lancet. 2008;371:164-75.

19. Piso B, Zechmeister-Koss I, Winkler R. Antenatal interventions to reduce preterm birth: an overview of Cochrane Systematic Reviews. BMC Res Notes. 2014;7:265.

20. Hassan SS, Romero R, Vidyadhari D, Fusey S, Baxter JK, Khandelwal M, et al. Vaginal progesterone reduces the rate of preterm birth in women with a sonographic short cervix: a multicenter, randomized, double-blind, placebocontrolled trial. Ultrasound Obstet Gynecol. 2011;38:18-31.

21. Fonseca EB, Celik E, Parra M, Singh M, Nicolaides KH. Fetal Medicine Foundation Second Trimester Screening Group. Progesterone and the risk of preterm birth among women with a short cervix. N Engl J Med. 2007;357:462-9.

22. DeFranco EA, O'Brien JM, Adair CD, Lewis DF, Hall DR, Fusey S, et al. Vaginal progesterone is associated with a decrease in risk for early preterm birth and improved neonatal outcome in women with a short cervix: a secondary analysis from a randomized, double-blind, placebo-controlled trial. Ultrasound Obstet Gynecol. 2007;5:697-705.

23. Cahill AG, Odibo AO, Caughey AB, Stamilio DM, Hassan SS, Macones GA, et al. Universal cervical length screening and treatment with vaginal progesterone to prevent preterm birth: a decision and economic analysis. Am J Obstet Gynecol. 2010;202:548.

24. O'Brien JM, Adair CD, Lewis DF, Hall DR, Defranco EA, Fusey S, et al. Progesterone vaginal gel for the reduction of recurrent preterm birth: primary results from a randomized, double-blind, placebo-controlled trial. Ultrasound Obstet Gynecol. 2007;30(5):687-96.

25. Tita AT, Rouse DJ. Progesterone for preterm birth prevention: an evolving intervention. Am J Obstet Gynecol. 2009;200:219-24.

26. Dodd JM, Flenady VJ, Cincotta R, Crowther CA. Progesterone for the prevention of preterm birth: a systematic review. Obstet Gynecol. 2008;112:127-34

27. Romero R, Nicolaides K, Conde-Agudelo A, Tabor A, O'Brien JM, Cetingoz E, et al. Vaginal progesterone in women with an asymptomatic sonographic short cervix in the midtrimester decreases preterm delivery and neonatal morbidity: a systematic review and metaanalysis of individual patient data. Am J Obstet Gynecol. 2012;206:124.

28. Farine D, Mundle WR, Dodd J, Basso M, Delisle MF, Grabowska K, et al. The use of progesterone for prevention of preterm birth. J Obstet Gynaecol Can. 2008;30:67-77.

29. Arabin B, Halbesma JR, Vork F, Hübener M, van Eyck J. Is treatment with vaginal pessaries an option in patients with a sonographically detected short cervix? J Perinat Med. 2003;31:122-33.

30. Goya M, Pratcorona L, Merced C, Rodó C, Valle L, Romero A, et al. Cervical pessary in pregnant women with a short cervix (PECEP): an open-label randomised controlled trial. Lancet. 2012;379:1800-6.

31. Abdel-Aleem H, Shaaban OM, Abdel-Aleem MA. Cervical pessary for preventing preterm birth. Cochrane Database Syst Rev. 2013;5, CD007873.

32. Liem SM, van Pampus MG, Mol BW, Bekedam DJ. Cervical pessaries for the prevention of preterm birth: a systematic review. Obstet Gynecol Int. 2013;2013:576723.

33. Acharya G, Eschler B, Grønberg M, Hentemann M, Ottersen T, Maltau JM. Noninvasive cerclage for the management of cervical incompetence: a prospective study. Arch Gynecol Obstet. 2006;273:283-7.

34. Kimber-Trojnar Z, Patro-Małysza J, Leszczyńska-Gorzelak B, Marciniak B, Oleszczuk J. Pessary use for the treatment of cervical incompetence and prevention of preterm labour. J Matern Fetal Neonatal Med. 2010;23:1493-9.

35. Newcomer J. Pessaries for the treatment of incompetent cervix and premature delivery. Obstet Gynecol Surv. 2000;55:443-8.

36. AEMPS. S.A.o.M.P. Monograph Product Progefik (progesterone). S.A.o.M Products, Editor. 2010. http://www.aemps.gob.es/cima/pdfs/es/ft/60879/ FT 60879.pdf. Accessed 10 Oct 2011

37. Alfirevic Z, Owen J, Carreras Moratonas E, Sharp AN, Szychowski JM, Goya M. Vaginal progesterone, cerclage or cervical pessary for preventing preterm birth in asymptomatic singleton pregnant women with a history of preterm birth and a sonographic short cervix. Ultrasound Obstet Gynecol. 2013;41:146-51. 
38. To MS, Skentou C, Chan C, Zagaliki A, Nicolaides KH. Cervical assessment at the routine 23-week scan: standardizing techniques. Ultrasound Obstet Gynecol. 2001;17:217-9.

39. Heath VC, Souka AP, Erasmus I, Gibb DM, Nicolaides KH. Cervical length at 23 weeks of gestation: the value of Shirodkar suture for the short cervix. Ultrasound Obstet Gynecol. 1998;12:318-22.

Submit your next manuscript to BioMed Central and take full advantage of:

- Convenient online submission

- Thorough peer review

- No space constraints or color figure charges

- Immediate publication on acceptance

- Inclusion in PubMed, CAS, Scopus and Google Scholar

- Research which is freely available for redistribution 